\title{
Rebuttal to: choice of prosthetic valve in a developing country
}

\author{
Iqbal H Jaffer, ${ }^{1,2}$ Richard P Whitlock ${ }^{2,3}$
}

${ }^{1}$ Thrombosis and

Atherosclerosis Research Institute, Hamilton, Ontario,

Canada

${ }^{2}$ Division of Cardiac Surgery, McMaster University, Hamilton, Ontario, Canada

${ }^{3}$ Population Health Research Institute, Hamilton, Ontario, Canada

\section{Correspondence to} Dr Richard P Whitlock, Population Health Research Institute, DBCVSRI,

Room 1C1-5B, 237 Barton

St. E., Hamilton, Ontario,

Canada L8L 2X2:

richard.whitlock@phri.ca

Accepted 17 February 2016

\section{SLinked}

- http://dx.doi.org/10.1136/ heartasia-2015-010660 - http://dx.doi.org/10.1136/ heartasia-2015-010650

CrossMark

To cite: Jaffer $\mathrm{IH}$,

Whitlock RP. Heart Asia 2016;8:73.
We read with interest the counterpoint suggesting that the best choice for the patient is a bioprosthetic valve. We acknowledge many of the points made by the authors, ${ }^{1}$ most importantly that the decision of valve prosthesis is a shared process between healthcare providers and patients. However, there several points that we feel need clarification.

The authors highlight the need for anticoagulation in the context of atrial fibrillation (AF), but then suggest that the differences in the International Normalised Ratio (INR) targets for patients with a mechanical heart valve and those in AF are substantially different. Looking at the evidence, however, would seem to suggest that the guidelines supporting higher anticoagulation for mechanical valves in the mitral position are based on small studies of low quality, and the strength for this recommendation is weak. ${ }^{2-5}$ We would argue that, in the context of all other aspects of anticoagulation medicine, whether it is AF or venous thromboembolism, higher risk does not confer higher anticoagulation targets. ${ }^{6}{ }^{7}$ We give the example of the $\mathrm{CHADS}_{2}$ score where a $\mathrm{CHADS}_{2}$ score of 2 or 6 has an annualised stroke risk of 4 and $18.2 \%$, respectively. Despite this, the INR target with a vitamin $\mathrm{k}$ antagonist for both types of patients is $2-3 .{ }^{6}$ We would further argue that more contemporary studies such as those from Dong et $a l^{8}$ have demonstrated that a lower INR in patients even with double valves is acceptable and safe as long as it is supplemented with low-dose aspirin — a drug that is widely used and available.

With respect to the argument from the authors about life expectancy, while we would not disagree with their analysis regarding the factors relating to life expectancy, we would question the importance of this discussion with regard to the patient at hand. Most of the literature supporting the early degeneration of bioprosthetic valves concentrates on the process of calcification that is higher in younger patients and is not related to the perceived potential life expectancy of any patient. ${ }^{9}$ That notwithstanding, even assuming a life expectancy of an Indian male to be 62.2 , that is nearly another 18 years to be expected, wherein the data suggest, this patient would require a much more risky reoperation..$^{10}$ To that end, we would still encourage this patient to undergo a mitral valve replacement with a mechanical heart valve.

Twitter Follow Richard Whitlock at @RichardWhitloc2 and Iqbal Jaffer at @ihjaffer

Competing interests $\mathrm{IHJ}$ discloses research support from Boehringer Ingelheim, CCS-Bayer Cardiovascular Trainee Award, and in-kind research support from Sorin Group, Canada. RPW discloses financial honoraria from Atricure.

Provenance and peer review Commissioned; internally peer reviewed.

\section{REFERENCES}

1 Choudhary SK, Talwar S, Airan B. Choice of Prosthetic Heart Valve in a Developing country. Heart Asia 2016;8. doi:10.1136/ heartasia-2015-010650

2 Koertke H, Zittermann A, Tenderich G, et al. Low-dose oral anticoagulation in patients with mechanical heart valve prostheses: final report from the early self-management anticoagulation trial II. Eur Heart J 2007;28:2479-84.

3 Hering D, Piper C, Bergemann R, et al. Thromboembolic and bleeding complications following St. Jude medical valve replacement: results of the German experience with low-intensity anticoagulation study. Chest 2005;127:53-9.

4 Vahanian A, Alfieri O, Andreotti F, et al. Guidelines on the management of valvular heart disease (version 2012): the Joint Task Force on the Management of Valvular Heart Disease of the European Society of Cardiology (ESC) and the European Association for Cardio-Thoracic Surgery (EACTS). Eur J Cardiothorac Surg 2012;42:S1-44.

5 Whitlock RP, Sun JC, Fremes SE, et al. Antithrombotic and thrombolytic therapy for valvular disease: antithrombotic therapy and prevention of thrombosis, 9th ed: American College of Chest Physicians Evidence-Based Clinical Practice Guidelines. Chest 2012;141(2 Suppl):e576S-600S.

6 You JJ, Singer DE, Howard PA, et al. Antithrombotic therapy for atrial fibrillation: antithrombotic therapy and prevention of thrombosis, 9th ed: American college of chest physicians evidence-based clinical practice guidelines. Chest 2012;141(2 Suppl):e531S-75S.

7 Kearon C, AkI EA, Ornelas J, et al. Antithrombotic therapy for VTE disease: CHEST guideline and expert panel report. Chest 2016;149:315-52.

8 Dong MF, Ma ZS, Ma SJ, et al. Anticoagulation therapy with combined low dose aspirin and warfarin following mechanical heart valve replacement. Thromb Res 2011;128:e91-4.

9 Schoen FJ. The first step to understanding valve failure: an overview of pathology. Eur J Cardiothorac Surg 1992;6(Suppl 1): S50-3.

10 Surgeons SoT. STS Risk Calculatorhttp://riskcalc.sts.org/ stswebriskcalc/-/calculate

This was originally published as an interactive clinical case on the Heart Asia blog at http://blogs.bmj.com/ heartasia/ in October 2015 under the title 'Choice of prosthesis in a young man with mitral valve disease'. Readers are invited to visit the blog post to vote on their preferred clinical approach and participate in the debate by leaving comments. 